\section{Title: PHYSICAL VAPOR DEPOSITED \\ ALUMINUM FOILS FOR HIGH ENERGY DENSITY PHYSICS EXPERIMENTS}

Author(s):
B. L. Barthell
MST-7
W. E. Anderson MST-7
V. M. Gomez MST-7
B. F. Henneke MST-7
J. E. Moore MST-7
G. A. Reeves MST-7
M. A. Salazar MST-7
J. D. Townsend MST-7

Submitted to:

10th IEEE International Pulsed Power Conference

Albuquerque, New Mexico

July 10-13, 1995

DISTRIBUTION OF THIS DOCUMENT IS UNLIMITEQ Wh $^{\prime}$

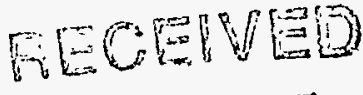

Alls 29 1995

\title{
OSTI
}

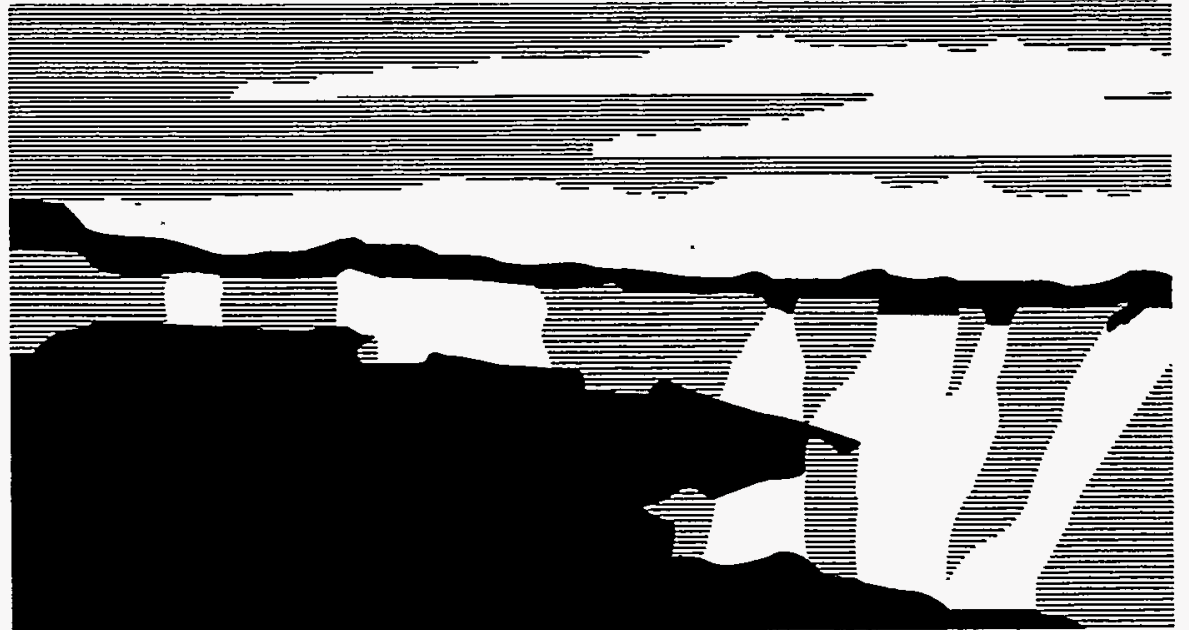

NATIONAL LABORATORY

Los Alamos National Laboratory, an affirmative action/equal opportunity employer, is operated by the University of California for the U.S. Department of Energy under contract W-7405-ENG-36. By acceptance of this article, the publisher recognizes that the U.S. Government retains a nonexclusive, royaltyfree license to publish or reproduce the published form of this contribution, or to allow others to do so, for U.S. Government purposes. The Los Alamos National Laboratory requests that the publisher identify this article as work performed under the auspices of the U.S. Department of Energy. 


\section{DISCLAIMER}

Portions of this document may be illegible in electronic image products: Images are produced from the best available original document. 


\title{
PHYSICAL VAPOR DEPOSITED ALUMINUM FOILS FOR HIGH ENERGY DENSITY PHYSICS EXPERIMENTS
}

\author{
B. L. Barthell, W. E. Anderson, V. M. Gomez, B. F. Henneke, \\ J. E. Moore, G. A. Reeves, M. A. Salazar, and J. D. Townsend \\ Los Alamos National Laboratory, Mail Stop E549 \\ Los Alamos, New Mexico 87545
}

\begin{abstract}
Fabrication of cylindrical aluminum load foils and graded thickness aluminum vacuum opening switch foils is described. Load foils are vaporized by joule heating and imploded by $\mathrm{J} \times \mathrm{B}$ forces to stagnate on axis and create soft $x$-rays. Plasma flow switch foils are mounted to shunt the vacuum power flow channel of a coaxial gun and are vaporized by joule heating. The resultant graded density plasma is magnetically driven down the annular power flow channel. Opening switch action occurs when the shunt plasma crosses a load slot in the center conductor. These foil components have been used in both the Pegasus and Procyon experiments.
\end{abstract}

\section{INTRODUCTION}

Cylindrical thin metal foils are of interest to a number of researchers conducting pulsed power experiments. The earliest work in this areas was carried out using commercially available flat foils that were simply wrapped around a pair of support rings to produce a foil cylinder. The seam at the point where the edges of the foil were joined was highly undesirable from the standpoint of implosion symmetry. It presented a region of essentially zero mass if a butt joint were formed or an area with twice the mass per unit area of the main body of the foil when an overlap joint was utilized. To overcome the problems associated with this joint, a technique for producing seamless foils was developed by Kindell et al. ${ }^{1}$ In their process, they utilized a cylindrical polymer substrate made according to the method of Grader et al. ${ }^{2}$ The product was not a pure metal foil but a composite consisting of a polymer film substrate with a continuous and uniform metal overlay. While this seamless polymer/metal laminate was an improvement over wrapped foils, it presented a number of problems in fabrication and use. The polymer film was formed from a noxious organic solvent by a dip-casting process. Because the polymer was vaporized in the experiment along with its metal coating, nonuniformity in the polymer film contributed to asymmetries in the implosion process. Thus, great care was required to produce a polymer film cylinder of uniform thickness, both along its length and around its perimeter. For metallization and subsequent experimental use, the polymer film had to be transferred to another fixture; during this transfer process, the thin polymer film frequently tore. Because of the laminate nature of the polymer/metal composite, wrinkles were invariably present in it. These wrinkles were undesirable, of course, from the standpoint of implosion symmetry. Finally, although the vaporization of the polymer film consumed a significant fraction of the energy available in the implosion process, it contributed nothing toward the goal of the experiments. Thus, it was necessary to keep the mass density of the polymer substrate as low as possible. This in turn led to the production of very thin films (about $1 \mu \mathrm{m}$ thick), which only exacerbated the handling problems described above.

The developments reported herein arose directly from attempts to improve and simplify the process for producing thin cylindrical foils. As a result of this work, unbacked thin metal foils with mass densities in the range of $50 \mu \mathrm{g} \mathrm{cm}^{-2}$ have been produced. These foils can be extremely smooth and almost wrinkle free.

\section{CYLINDRICAL LOAD FOILS-SUBSTRATE}

A search was conducted several years ago for an improved polymer substrate. ${ }^{3}$ The criteria for candidate polymers included the following:

- The material was required to be an inherently good film former to produce films with the strength and flexibility needed to withstand the handling involved in the fabrication, transfer, and metalization processes. 
- The polymer film had to separate readily from the ring without tearing or damaging the surface of the film.

- The film had to exhibit excellent surface properties, being free from bubbles, flecks and other imperfections that would tend to be replicated in the metal layer deposited onto it.

- Finally, the polymer film had to be readily soluble after metalization.

Examination of the available literature indicated that poly(vinyl alcohol) could readily meet the first three criteria. Experiments proved that this substance could also fulfill the last criterion. The fact that poly(vinyl alcohol) is water soluble greatly simplified the preparation of the polymer films since no noxious vapors were released at any stage in the process. In addition, since poly (vinyl alcohol) is nontoxic, waste materials can be disposed of by simply being flushed down the drain.

\section{LOAD FOIL FABRICATION}

Although the method of Kindell et al. ' has remained the basis for Los Alamos load foil fabrication, the technique itself has been greatly modified. A polymer film substrate is formed by dipping a lapped stainless steel ring into a solution consisting of $9.8 \%$ poly (vinyl alcohol), $2.4 \%$ glycerin, and $87.8 \%$ water. Borosilicate glass rings have been used recently for reasons of economy. The poly(vinyl alcohol) is typically $88 \%$ hydrolyzed with an average molecular weight of about 110,000 . The rates of immersion of the forming ring and of the removal of the forming ring from the casting solution are not closely controlled. Excess liquid is allowed to drip away from the forming ring before the sample is placed in a forced-air oven at $70^{\circ} \mathrm{C}$ for an hour to evaporate the water. After this treatment, the polymer film can readily be pulled away from the interior surface of the ring. In some cases, forming rings are pretreated with a commercial mold release spray to facilitate removal of the polymer film from the ring (Mold Release 225 obtained from RAM Chemical, Gardena, California). Glass rings may require a surface treatment after a period of use. Burnishing a fluoropolymer coating (Du Pont AF 2400) applied as a fluorocarbon solvent solution has proven effective.

After the polymer film has been removed from the forming ring, it is pulled over ring electrodes that are supported on a demountable fixture used during foil fabrication and at the pulse power facility for foil insertion. Forming rings are sized to give a cylindrical polymer film greater by $0.5 \mathrm{~mm}$ in diameter than the ring electrodes. The polymer film is attached to the outer edge of each ring electrode by means of a cotton swab wetted with water to dissolve away excess poly (vinyl alcohol) film, while at the same time a portion of the dissolved polymer is utilized as a glue to hold the film to the electrode (Fig. 1). The film-electrode assembly is immersed in isopropyl alcohol for $30 \mathrm{sec}$ to extract a portion of the glycerin plasticizer and is subsequently dried for $10 \mathrm{~min}$ at $70^{\circ} \mathrm{C}$. This treatment causes the film to shrink snugly around the electrode rings.

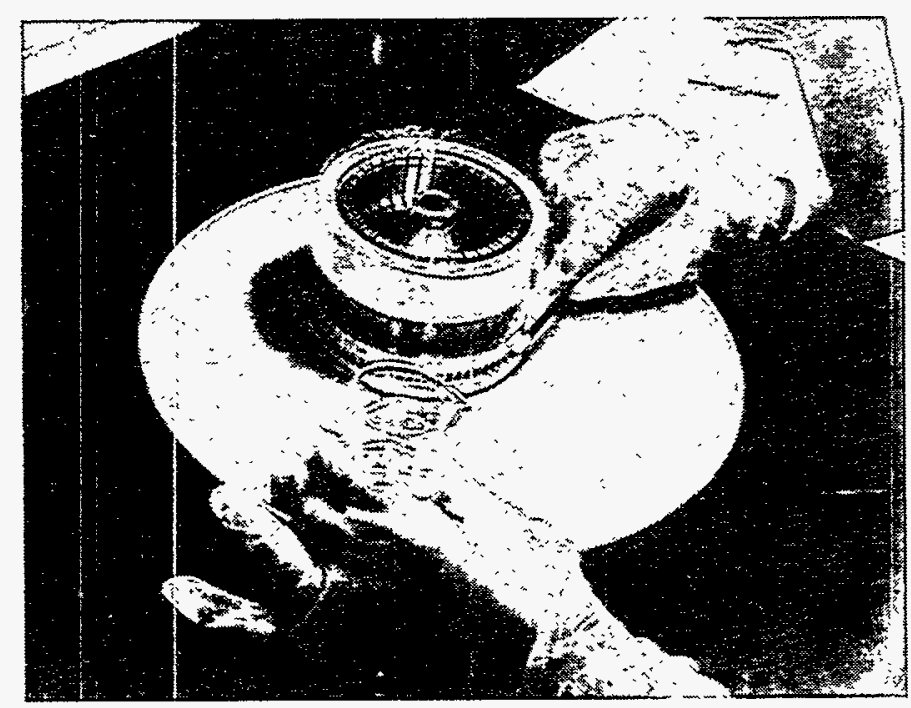

Fig. 1. Attachment of polymer film substrate to outer edge of ring electrode. 
The fixture, with the polymer film suspended tautly across the electrodes, is mounted in a rotator for vacuum deposition of the metal foil. Metal vapor is generated from a commercial electron-beam-heated vapor deposition source. The coating assembly is designed to confine the angle of incidence of the metal vapor onto the cylindrical substrate to $\pm 60 \mathrm{deg}$ or less from the normal to the cylinder surface (Fig. 2). Oxygen gas is admitted intermittently to the vacuum system in short pulses to produce a partial oxide layer at about every $0.1 \mathrm{~mm}$ of deposit when aluminum foils are produced. Reasons for this aluminum deposition procedure, termed the Los Alamos pulsed gas process (PGP), are evident from the next section, and further details may be found in the cited references.

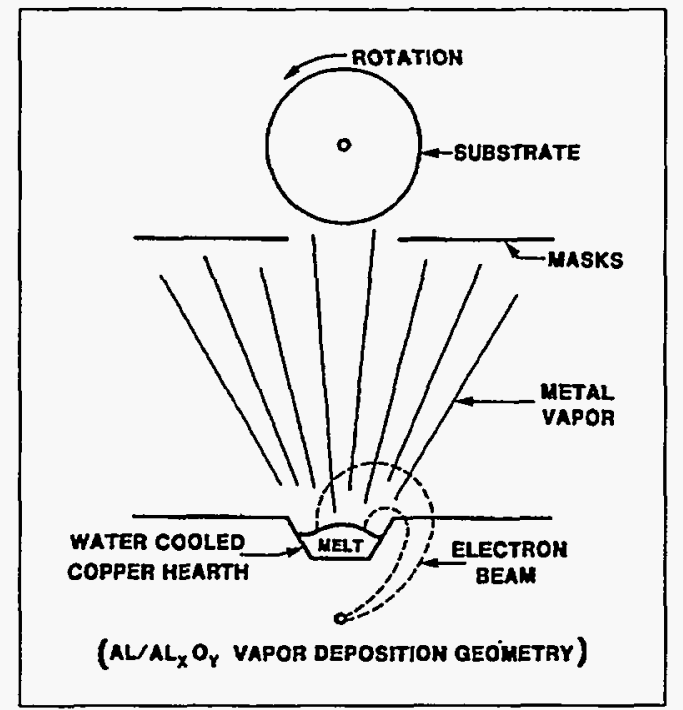

Fig. 2. Vapor deposition. The angle of incidence of the metal vapor onto the cylindrical substrate is confined to $\pm 60 \mathrm{deg}$.

In the final step of the process, the metalized film/foil composite is placed in a large beaker, which is then filled with water at a rate of $0.5 \mathrm{~mm} \mathrm{~min}^{-1}$ to dissolve the polymer backing. Care is required to prevent rupture of the metal foil when the foil/polymer couple is released. The temperature of the water bath is maintained at $35^{\circ}-45^{\circ} \mathrm{C}$. Two drops of liquid dish-washing detergent are added to lower the surface tension and to ensure uniform wetting of all surfaces. After the fixture has been fully immersed, the water is slowly drained through a drip valve near the bottom of the beaker at a rate of about $0.5 \mathrm{ml} \mathrm{min}^{-1}$. The foil, now unbacked, is allowed to air-dry before being placed in a closed container for storage prior to use.

\section{VAPOR-DEPOSITED AL/AL $\mathrm{O}_{\mathbf{y}}$ METALLURGY}

A method to fabricate high yield strength materials, proposed by Koehler, ${ }^{4}$ is to alternate thin layers of a highshear modulus material with those of a low-shear modulus material. The layers must be less than 100 atomic layers in thickness and be single crystals of similar lattice spacing epitaxially grown on top of each other. The mechanical effect would be to inhibit dislocation formation and mobility of dislocations through the solid. As such, the stress required to move a dislocation through the laminate can be on the order of $1 \%$ of the lower modulus material.

A novel technique has been developed by Springer et al. that produces a laminate of $\mathrm{Al} / \mathrm{Al}_{\mathrm{x}} \mathrm{O}_{\mathrm{y}}$ by a pulsed gas process (Fig. 3). ${ }^{5}$ Samples, $25 \mu \mathrm{m}$ and thicker, have been readily produced on a rotating cylindrical substrate using angle of incidence limiting flux masks in an electron-beam gun vapor deposition system. Under the favorable conditions described in the reference, the surface finish of the growing deposit appears to remain as smooth as the substrate. Tensile testing data show the material obeys a Hall-Petch relationship for yield strength as a function of pulse spacing, reduced by a factor of 0.84 in cylindrical geometry from that predicted for flat plate geometry. The PGP is used to enhance foil tensile strength in the fabrication of aluminum load foils, described above, and in the fabrication of aluminum switch foils, described below. 


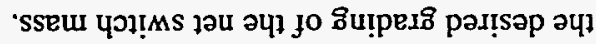

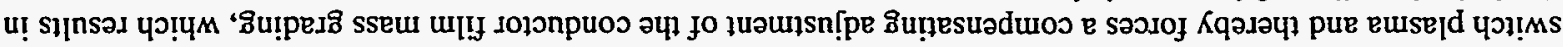

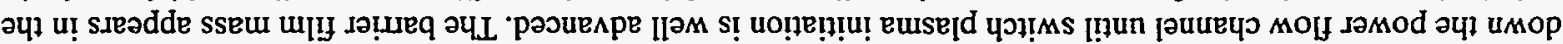

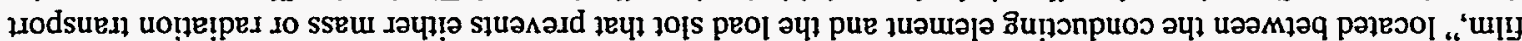

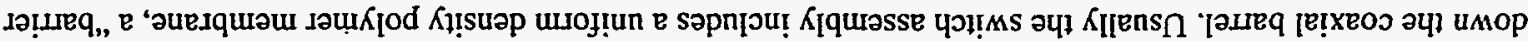

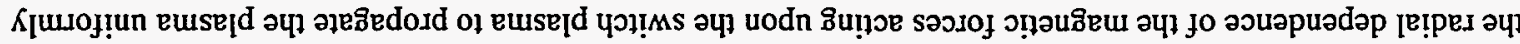

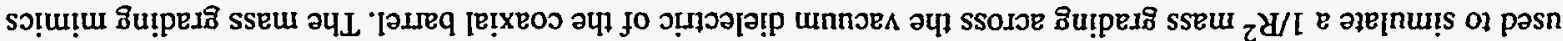

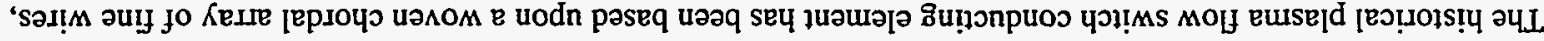

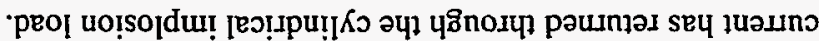

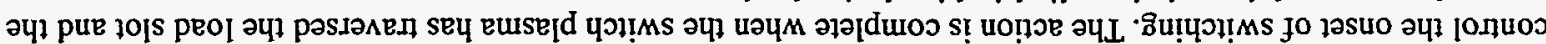

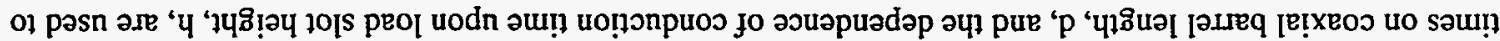

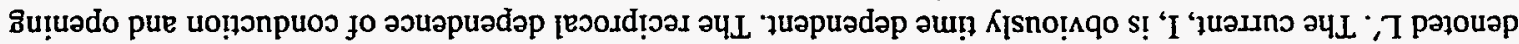

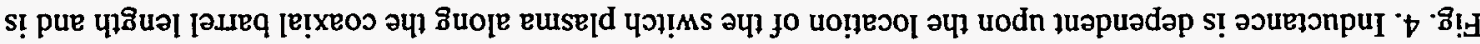

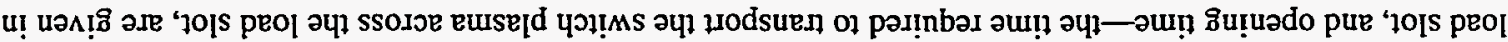

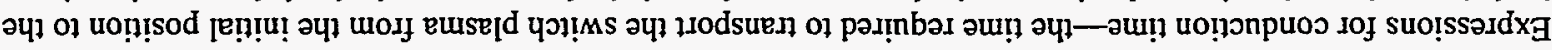

uo!̣!sod peol

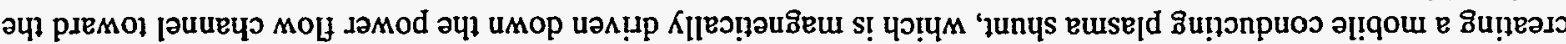

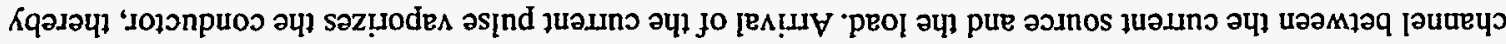

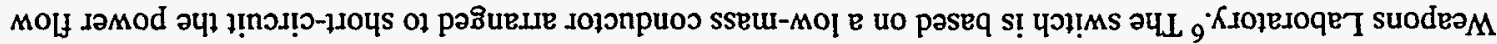
әวدо

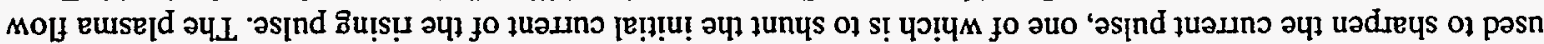

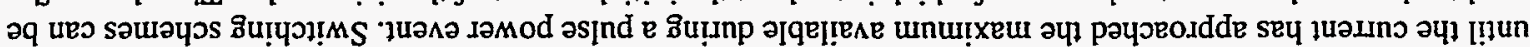

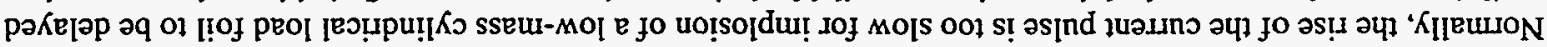

\section{HOLIMS DNING WO WRDVA MOTH VWSVTd TIOH GGZIXOdVA}
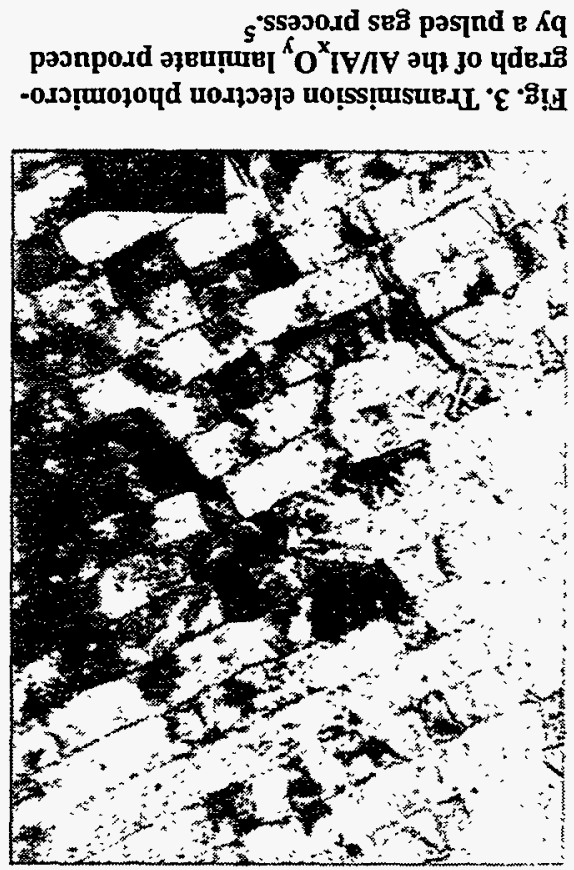


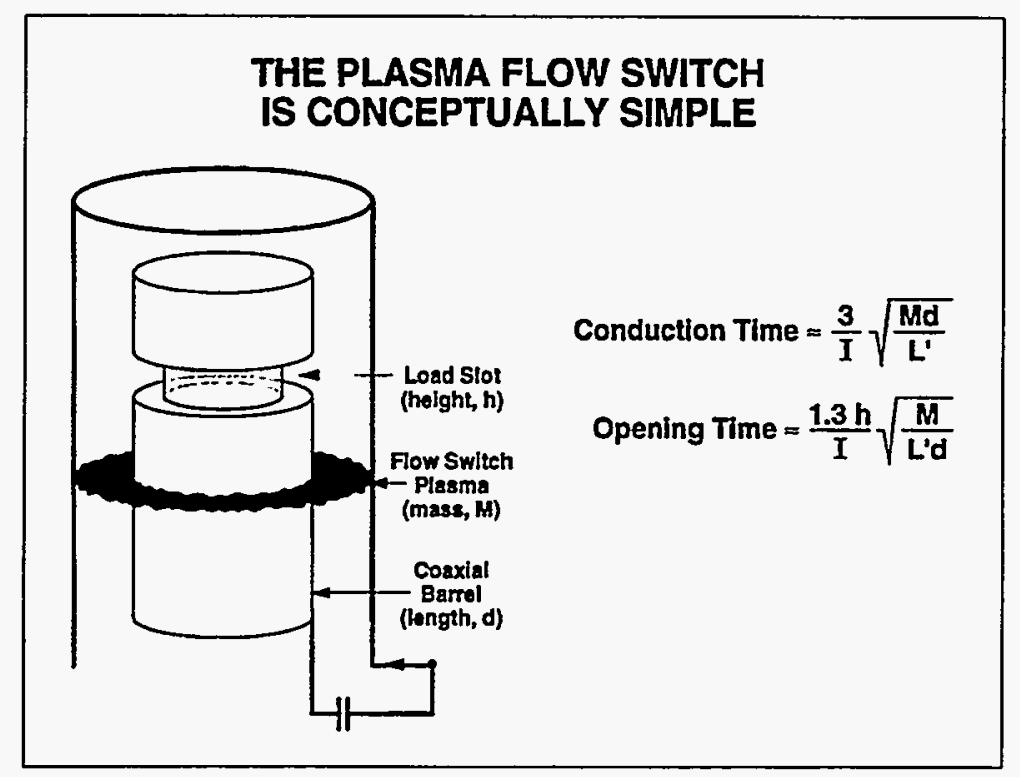

Fig. 4. Principles of the plasma flow switch.

Some recent Los Alamos designs have replaced the traditional wire conductors with a continuous graded aluminum foil conductor to provide better switch plasma uniformly, faster plasma initiation, and the prospect of greater variation of radial mass grading in flow switch designs. Graded aluminum foil-based plasma flow switches with polyethylene terephthalate (PET) barrier films have been used at both the Pegasus-II facility (50 $\mathrm{mg}$ and $100 \mathrm{mg}$, $1 / R^{2}$ net), with Procyon assemblies ( $200 \mathrm{mg}, 1 / \mathrm{R}$ net) and in a complex reversing gradient gating design at Pegasus-II. ${ }^{7,8}$ The coaxial gun of both facilities has an outside diameter of 8 in. and an inside diameter of 6 in.; therefore, the desired thickness grading occurs over a radial distance of $2.54 \mathrm{~cm}$.

\section{GRADED ALUMINUM SWITCH FOIL FABRICATION}

Radially graded planar aluminum switch foils are fabricated by physical vapor deposition (PVD), using generally similar procedures as those described in the fabrication of load foils, including use of the pulse gas process to strengthen the aluminum. Mass grading involves the use of sheet metal masks to intercept aluminum vapor in locations where foil thickness is to be reduced. Flat, smooth glass disks, 9 in. in diameter, are edge supported and rotated on axis in the coater to serve as a substrate for graded foil deposition. Cesium iodide or a similar watersoluble ionic salt is first deposited to serve as a parting layer, followed immediately by deposition of aluminum. Aluminum thickness is controlled by quartz crystal deposition monitor. Depositions on step-masked witness slides precede and follow graded foil deposition to provide an average value of graded thickness obtained by profilometer measurement. A nominally $8 \mathrm{in}$. inside diameter, $1 \mathrm{~cm}$ wide Mylar ring is centered and glued to the foil after the metallized substrate disk from the coater has been removed. Exact dimensions vary slightly between the two-pulse power facilities. The glass substrate is propped at an angle in the bottom of a rectangular plastic tank. Tap water is admitted slowly to release the foil along the contact line and to allow the freed portion to float on the surface. The free foil is collected from below on a tissue and dried, after which it can readily be handled by the Mylar ring.

Plasma flow switch assemblies are completed by assembling a sequence of metal rings designed to extend the inner and outer conductors of the pulse power facility coaxial barrels (Fig. 5). As the assembly proceeds, the graded aluminum foil and an area of lightly pretensioned PET membrane supported by an oversized frame are glued to the rings at appropriate times, aided by precision alignment fixtures. Differences in the hardware of the two facilities require minor variations in procedure to assemble the switches. After gluing, the center section of each foil and membrane is cut and measured for conformance to specification. 


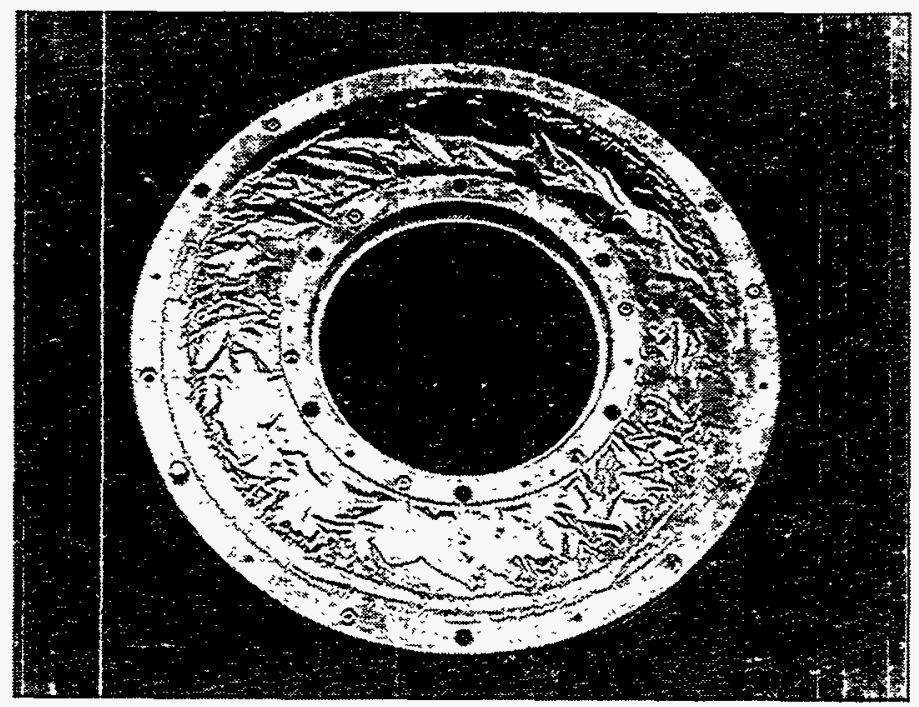

Fig. 5. Plasma flow switch assembly.

\section{CONCLUSIONS}

We have demonstrated that unbacked thin metal foils of multiple micron and of submicron thicknesses can be produced by electron beam vapor deposition. Both poly(vinyl alcohol) cast film and high-quality commercial glass, with a vapor-deposited salt release agent, provide excellent substrates for the aluminum foil deposition process. Either PVA or salt is readily removed by water after the foil has been fabricated, usually without causing damage. As a result of these developments, foils of higher quality, lower areal densities, and specified graded areal density, beyond those foils which have previously been available, can be provided for Los Alamos High Energy Density Physics Program experiments.

\section{REFERENCES}

1. F. W. Kindell, R. E. Reinovsky, and M. C. Clark, Review of Scientific Instruments 50, 1550-1552 (1979).

2. R. J. Grader, R. W. Hill, C. W. McGoff, D. S. Salmi, and J. P. Stoering, Review of Scientific Instruments $\mathbf{4 2}$, 465-467 (1973).

3. D. V. Duchane and B. L. Barthell, "Unbacked Cylindrical Metal Foils of Submicron Thickness," Thin Solid Films 107, 373-378 (1983).

4. J. S. Koehler, Physical Review B: Condensed Matter 2, 547 (1970).

5. R. W. Springer, B. L. Barthell, and D. Rohr, "Quantitative Characterization of High Strength Aluminum Foils Vapor Deposited on Curved Surfaces," Journal of Vacuum Science and Technology 17, 437-440 (1980).

6. W. L. Baker et al. "Plasma Flow Switch Driven Implosions," Proceedings of the Megagauss Fields and Pulsed Power Systems, 1989, V. M. Titov and G. A Shvetsov, Eds. (Nova Science Publishers, New York, 1990), pp. 615-622.

7. J. R. Benage, Jr., et al., "Plasma Flow Switch Experiments on Procyon," Proceedings of the 1Oth IEEE Pulsed Power Conference (1995).

8. F. Wysocki et al., "Plasma Gate Switch Experiment on Pegasus II," Proceedings of the IOth IEEE Pulsed Power Conference (1995). 